\title{
Social \& Behavioural Problems among School Going Adolescents of Garhwal region of Uttarakhand
}

\section{Prachi Kothari ${ }^{1}$, Ashok Kumar Srivastava ${ }^{2}$, Neha Sharma ${ }^{3}$}

${ }^{1}$ M.Sc. Epidemiology, Department of Community Medicine, Himalayan Institute of Medical Sciences, Swami Rama Himalayan University, Dehradun, Uttarakhand; ${ }^{2}$ Professor, Department of Community Medicine, Himalayan Institute of Medical Sciences, Swami Rama Himalayan University, Dehradun, Uttarakhand; ${ }^{3}$ Assistant Professor, Department of Community Medicine, Himalayan Institute of Medical Sciences, Swami Rama Himalayan University, Dehradun, Uttarakhand

\begin{tabular}{|l|l|l|l|l|l|l|l|}
\hline Abstract & Introduction & Methodology & Results & Conclusion & References & Citation & Tables/ Figures \\
\hline
\end{tabular}

\section{Corresponding Author}

Dr Ashok Kumar Srivastava, Professor, Department of Community Medicine, Himalayan Institute of Medical Sciences, Swami Rama Himalayan University, Dehradun, Uttarakhand-248016

E Mail ID: drsrivastavaak@gmail.com

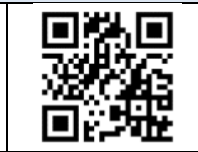

\section{Citation}

Kothari P, Srivastava AK, Sharma N. Social \& Behavioural Problems among School Going Adolescents of Garhwal region of Uttarakhand. Indian J Comm Health. 2021;33(1):116-122. https://doi.org/10.47203/IJCH.2021.v33i01.016

Source of Funding: Nil Conflict of Interest: None declared

\section{Article Cycle}

Received: 02/02/2021; Revision: 21/02/2021; Accepted: 05/03/2021; Published: 31/03/2021

This work is licensed under a Creative Commons Attribution 4.0 International License.

\section{Abstract}

Background: Mental health disorder is a major cause of impairment in youth aged between 9 to 17 years as one in every fifth youth has a mental disorder. In India, the prevalence of mental problems among adolescents is $14.3 \%$. Objective: To find out the proportion of social and behavioural problems among adolescents and their association with the sociodemographic factors. Methods: A cross-sectional study was carried out among 150 school going adolescents (11-17years). All the study participants were recruited through non-probability sampling technique. Data was collected through Google Forms. For assessing the social and behavioural problems, Strength and Difficulty questionnaire (SDQ) was used. Result: There were 76 (50.7\%) males and 74 (49.3\%) females in this study. $16 \%$ of school going children were categorized as "abnormal", $12 \%$ as borderline and $72 . \%$ as normal for social and behavioural problems based on scores of SDQ. The findings have implications that gender do play a role in affecting mental health status.Conclusions: Mental health problems are one of the most common and highly prevalent disorders among adolescents in India. For addressing psycho-social problems among adolescents there is a dire need of counsellors. Training of parents as well as teachers should be conducted for timely intervention.

\section{Keywords}

Mental Health; Adolescents; SDQ

\section{Introduction}

The total population of India is about 1.35 billion, (1) out of which 253.2 million are adolescents which means adolescents contribute to 20.9 of the total population, (2) and the total population of Uttarakhand is 10.39 million in which $22 \%$ are adolescents. (3) Adolescence is a formative and unique time. "WHO defines an adolescent as any person between ages 10 to 19 years" (4). Various changes like, emotional, physical, and social, including violence or abuse, are the cause of various types of mental sickness in adolescents. During adolescent age protection of adolescents from risk factors and encouraging psychological wellbeing is necessary for their physical as well as mental health. (5) According to WHO "Child and adolescent mental 
health is defined as the capacity to achieve and maintain optimal psychological functioning and wellbeing. It is causally related to the level reached and competence achieved in psychological and social functioning". (6) The definition of mental health by the WHO is described as "state of well-being in which the individual realizes his or her own abilities, can cope with the normal stresses of life, can work productively, and is able to make a contribution to his or her community".(7) Mental health disorder is a major cause of impairment in youth aged between 9 to 17 years as one in every fifth youth has a mental disorder. (8) out of all these only one third receive appropriate medical treatment. (8) Treatment for psychological disorders starts 6 to 23 years after onset, whereas disorders start by age 14 . (8) Adequate data on the prevalence of mental disorders among school going adolescents in Uttarakhand is still lacking, thus this study was planned to determine the proportion of social and behavioural problems among adolescents and its association with the sociodemographic factors.

\section{Aims \& Objectives}

1. To assess the proportion of social and behavioural problems among school going adolescents using Strength \& Difficulty Questionnaire (SDQ).

2. To find out the association between sociodemographic factors and mental health status of school going adolescents.

\section{Material \& Methods}

A cross-sectional study was conducted among school going adolescents (11 to 17 years) of Tehri District, between April 2020 to May 2020. Total 150 students were enrolled in the study through non-probability sampling technique-Convenient sampling. Study participants were enrolled in the study through emails and other social media Apps and they were requested to forward the link of google form to their acquaintances. Respondents who were using a social media and gave consent for the study were included. Respondents who were already diagnosed with some mental health issue were not included in the study.

Data collection: Data was collected through Google form. Section A consisted of questions pertaining to sociodemographic details. Section B had questions related to mental health of adolescents for which Strength and Difficulty questionnaire (SDQ) was used. (9) This is a 25 -item self-reported questionnaire. The 25 questions are divided into five categories: emotional symptoms, conduct problems, hyperactivity/inattention, peer relationship problems and pro-social behavior having five questions in each category. Thus, measures both strengths and difficulties behavioral and emotional attributes on a 3-point Likert type scale ( $0=$ Not true, 1 = Somewhat true, 2 = Certainly true).

Procedure: A pilot study was executed through Google Forms on 10 individuals. After the necessary changes, google forms were forwarded via e-mails and other social media Apps like WhatsApp, Facebook, and Instagram through convenient sampling technique to the study participants. As study participants were invited through social media i.e. via email/WhatsApp/Facebook/Instagram, a brief description/instruction regarding the research purpose was made clear to them. Their participation in the study was only after they gave confirmation through the consent form. The study participants were requested to forward the link of google form survey to their friends and acquaintances to fetch more responses from their network. Privacy and confidentiality of the collected information was ensured.

Statistical Analyses: The data was entered in MS excel 2010. Statistical analysis was performed using SPSS software version 22. Descriptive statistics were presented in mean \pm SD (for quantitative data). Graphical representation of the variables was shown to understand the results clearly. Chi-square and Fisher Exact test was used to check the association between the dependent and independent variables. A minimum two-sided $95 \%$ confidence interval with $\mathrm{p}$ value $<0.05$ was considered as statistically significant. used to check the association between the dependent and independent variables. A minimum two-sided $95 \%$ confidence interval with $p$ value $<0.05$ was considered as statistically significant.

\section{Results}

(Table 1) Total 150 school going adolescents aged between 11 to 17 years from Tehri district of Uttarakhand were included in the study, which comprised of $76(50.7 \%)$ males and 74 (49.3\%) females. Of these, $36.8 \%$ participants were aged between 11 to 15 and $61.8 \%$ were aged between 16 to 17 . The mean age of study participants was observed to be $14.66 \pm 1.88$ years. Most of the study participants were Hindu (94.7\%). Among the parents 
of the study participants, majority $(45.3 \%)$ of fathers were graduate while majority $(45.3 \%)$ of mothers received education up to 12 th class. Socio economic status of study participants depicts that majority $(71.3 \%)$ of them belonged to upper middle class followed by upper class (24.7\%). Most (64.7\%) of study participants lived in a nuclear family and majority $(66.7 \%)$ of study participants were seeking education from private schools.

(Table 2) Shows the subscales score of SDQ to assess mental health disorders among the study participants. On individual behavioural subset scores, $6.7 \%$ were rated abnormal under emotional subset, followed by $8.7 \%$ under hyperactivity subset, $7.3 \%$ under peer pressure, $6.7 \%$ under prosocial behaviour subset and $6.0 \%$ under conduct problems. (Figure 1) Depicts the total difficulty score of the study participants where $72 \%$ of the study participants had normal total difficulty score and $16 \%$ had abnormal total difficulty score.

Based on gender predilection, girls had high abnormal scores in all the behavioural subsets with highest in conduct problem followed by hyperactivity (92.3\%), peer problem (85.7\%), emotional problems $(80.0 \%)$, total difficulty scores (62.5\%) and pro-social behaviour (60.0\%) respectively as compared to boys study participants. None of the boys were rated as abnormal in conduct subset. Behavioural subset like emotional problems, conduct problems, hyperactivity and peer problem were found to be significantly associated with the gender $(p<0.05)$. (Table 3 )

On comparing the behavioural subset scores with the type of school of the study participants, study participants of private schools had high abnormal scores in all the behavioural subsets with highest in conduct problem followed by hyperactivity $(92.3 \%)$, emotional problems $(80.0 \%)$, pro-social behaviour $(80.0 \%)$ and peer problem $(71.4 \%)$, respectively as compared to study participants of Government school. None of the study participant of Government school were rated as abnormal in conduct subset. Behavioural subset like conduct problems and hyperactivity were found to be significantly associated with the type of school $(p<0.05)$. (Table 4)

\section{Discussion}

There is meagre knowledge available related to adolescents emotional and behavioural issues in Uttarakhand. The study provides a snapshot of liability of developing mental health problems among 150 school going adolescents aged 11-17 years of Tehri district of Uttarakhand, India. Most of the previous studies have reported the prevalence of abnormal SDQ among Indian children from 6-17\%. In our study, $24 / 150(16 \%)$ of school going children were categorized as "abnormal", 18/150 (12\%) as borderline and $108 / 150(72 \%)$ as normal based on self-rating using SDQ. The findings were in align with the findings of Pahwa et al that identified around $14.7 \%$ of their study participants to be abnormal, $25.5 \%$ participants as borderline and 59.8\% participants as normal. (10) A study done on Malaysian population showed $80 \%$ in abnormal category. Thus, such kind of difference is due to varied instruments and study designs. However, screening tools usually yield higher results as compared to diagnostic tools. Therefore, further evaluation of study participants falling under abnormal and borderline categories should be followed up for better diagnosis and treatment. (11) On the individual behavioural subsets scores, hyperactivity $(8.3 \%)$ was found to be having most abnormal scores followed by peer problems (7.3\%) and emotional problems (6.7\%) and pro-social behaviour (6.7\%) respectively. A study by Nair et al also showed peer problem and emotional problem as most common mental health problem in their study. (12) In the present study, girls reported more emotional and behavioural problems and conduct problems, emotional problems, peer problems and hyperactivity were significantly associated with gender. A study conducted by Greally et al showed similar results in which abnormal SDQ score were more common in girls as compared to boys. (13) Interestingly, in contrast to previous research, the findings of the present study do not support the inclination towards higher conduct problems and hyperactivity among males. Our result findings are in accord with the study by Bhola et al. (14) The proportion of school going adolescents in abnormal category for mental health problems was more in students studying in private school (20\%) as compared to Government school students (8\%) in this study. On analysing individual behavioural subset scores private school students had highest abnormal scores in conduct problems followed by hyperactivity and both the subsets were significantly associated with school type. Pahwa et al in their study showed the prevalence from $17.94 \%$ and $20.61 \%$ in the private schools in the urban and rural area respectively while $20.96 \%$ and $22.17 \%$ among 
Government school in urban \& rural area. According to previous study parents who ban their children more and do not encourage them to talk about their friends at home, those students had a higher SDQ score. (15) Also, an earlier study revealed that after school entertainment is also helpful in decreasing mental disorder among students. (16)

\section{Conclusion}

Mental health problems are the most common and highly prevalent among adolescents in India. This study focused on identifying the mental health status of the school going adolescents. The findings have implications for understanding gender-specific vulnerabilities, family contextual variables. A significant proportion of school-going adolescents harbour mental health problems, which accounted for $16 \%$ of the students who participated in our study that were found to be having abnormal scores according to Strength and Difficulty Questionnaire. All mental health issues were found to be more prevalent among the girls and students belonging to the nuclear family. Among individual behaviour subsets, hyperactivity and peer problems were found to be the most concerned areas for adolescents. This study also shows that the sociodemographic factors also plays an important role in the mental health status of the adolescents as factors like gender, type of school, type of family were found to be significantly associated with the social and behavioural problems of adolescents. So, for improving the mental health status of adolescents and prevent them from various kind of psychiatric disorders, family members and teachers both also need to take care of children's emotions and should take appropriate action to improve their mental health.

\section{Recommendation}

The adolescents are future of the nation and tomorrow's adult. They must be secure of social, emotional, and moral stabilities for maintenance and preservation of their health. Since many adolescents do experience symptoms but does not share, so there should be planned and focused youth mental health services for prevention and management of mental illness.

\section{Limitation of the study}

The finding of the study cannot be generalized, as it being limited to small sample size. Being also a crosssectional study, cause effect relationship cannot be established. Since the study was conducted through google forms, acquiescence bias cannot be ruled out.

\section{Relevance of the study}

The present study emphasizes that the adolescents have social and behavioral disorders and they cannot be ignored. They can cause detrimental affect on their growth and development. One needs to understand that mental health disorder is a major cause of impairment among youths and these needs be addressed at the earliest before it becomes an epidemic. Adolescent health clinic is the need of the hour right from grassroot level to tertiary care level.

\section{Authors Contribution}

All the authors have made considerable contribution to the design of the "study, collection, analysis and interpretation of data as well as preparation of manuscript".

\section{Acknowledgement}

The authors are extremely grateful and thankful to the "Department of Community Medicine" (Himalayan Institute of Medical Sciences, Dehradun) and "Swami Rama Himalayan University".

\section{References}

1. United Nations Department of Economic and Social Affairs, Population Division. Overall total population" - World Population Prospects. Weblog. Available from https://population.un.org/wpp/ [Accessed on Feb 26, 2021].

2. Census of India 2011. Profile of Adolescents and Youth in India. Available from: https://india.unfpa.org/sites/default/files/pub-pdf/4A\%26YProfile StateofLiteracy.pdf .

3. India population 2019.com. Population of India 2019. [Online]. Available from:

https://indiapopulation2019.com/\#: :text=2018\%20\%E2\%80 \%93\%201.35352\%20Billion\&text=Hence\%2C\%20the\%20popul ation\%20of\%20India,according\%20to\%20estimates\%3D\%201. 372224\%20Billion . [Accessed on Feb 26, 2021]

4. World health organization, W.H.O. World Health Organization, Western Pacific, Adolescent health. Available from: https://www.who.int/westernpacific/healthtopics/adolescent-health/2 [Accessed on Feb 26, 2021].

5. World Health Organization. Adolescent mental health. Available at: https://www.who.int/news-room/factsheets/detail/adolescent-mental-health

6. WHO "Child and Adolescent Mental Health Policies and Plans", Mental Health Policy and Service Guidance Package. 2005 p.7. Available http://www.who.int/mental health/policy/Childado mh mo dule.pdf

7. World Health Organization. Mental health: strengthening our response. https://www.who.int/news-room/factsheets/detail/mental-health-strengthening-our-response [Accessed on Feb 26, 2021].

8. U.S. Department of Health and Human Services. Mental Health: a report of the Surgeon General. Available at: 
INDIAN JOURNAL OF COMMUNITY HEALTH / VOL 33 / ISSUE NO 01 / JAN- MAR 2021 https://www.surgeongeneral.gov/library/mentalhealth/home .html . Retrieved January 30, 2017. Rockville (MD): HHS;1999

9. Robert Goodman. Primary Mental Health Care Minimum Data Set: Scoring the Strengths and Difficulties Questionnaire, Department of Health. 2002;19.

10. Pahwa MG, Sidhu BS, Balgir RS. A study of psychiatric morbidity among school going adolescents. Indian J Psychiatry. 2019;61(2):198-203.

doi: 10.4103/psychiatry.IndianJPsychiatry_35_16. PMID: 30992616; PMCID: PMC6425794.[PubMed]

11. Pandiyan NJ, Hedge A. Strength and difficulties questionnaire: A tool as prerequisite to measure child's mental health problems attending dental clinics. J Indian Soc Pedod Prev Dent. 2016;34(4):354-8. doi: 10.4103/0970-4388.191417. PMID: 27681399.[PubMed].

12. Nair S, Ganjiwale J, Kharod N, Varma J, Nimbalkar SM. Epidemiological survey of mental health in adolescent school children of Gujarat, India. BMJ Paediatr Open.
[Social \& Behavioural Problems...] | Kothari P et al 2017;1(1):e000139. doi: 10.1136/bmjpo-2017-000139. PMID: 29637154; PMCID: PMC5862196.[PubMed].

13. Greally $P$, Kelleher I, Murphy J, Cannon M. Assessment of the mental health of Irish Adolescents in the community. RCSI Student Medical Journal. 2009;3(1):33-35.

14. Bhola P, Sathyanarayanan V, Rekha DP, Daniel S, Thomas T. Assessment of Self- Reported Emotional and Behavioral Difficulties Among Pre-University College Students in Bangalore, India. Indian J Community Med. 2016 ;41(2):146-50. doi: 10.4103/0970-0218.177536. PMID: 27051090; PMCID: PMC4799638.[PubMed]

15. D K, Bose SC. Factors influencing school performance among adolescents in urban and rural areas of Puducherry. International J Recent Sci Res 2012;3:953-6.

16. Chauhan S, Lal P, Nayak H. Prevalence of depression among school children aged 15 years and above in a public school in Noida. J Acad Industrial Res 2014;3:269.

\section{Tables}

\section{TABLE 1 SOCIO-DEMOGRAPHIC DETAILS OF THE STUDY PARTICIPANTS}

\begin{tabular}{|c|c|c|}
\hline \multirow{2}{*}{ Variables } & \multicolumn{2}{|c|}{ Study Participants (N-150) } \\
\hline & Number & Percentage \\
\hline \multicolumn{3}{|l|}{ Gender } \\
\hline Male & 76 & 50.7 \\
\hline Female & 74 & 49.3 \\
\hline \multicolumn{3}{|l|}{ Religion } \\
\hline Hindu & 142 & 94.7 \\
\hline Others & 8 & 5.3 \\
\hline \multicolumn{3}{|l|}{ Education of Mother } \\
\hline Up to 5 th class & 13 & 8.6 \\
\hline Up to 12 th class & 68 & 45.3 \\
\hline Graduate & 47 & 31.3 \\
\hline Postgraduate \& above & 22 & 14.7 \\
\hline \multicolumn{3}{|l|}{ Education of Father } \\
\hline Up to 5 th class & 7 & 4.6 \\
\hline Up to 12 th class & 36 & 24.0 \\
\hline Graduate & 68 & 45.3 \\
\hline Postgraduate \& above & 39 & 26.0 \\
\hline \multicolumn{3}{|l|}{ Occupation of Mother } \\
\hline Employed & 46 & 30.6 \\
\hline Unemployed & 104 & 69.3 \\
\hline \multicolumn{3}{|l|}{ Occupation of Father } \\
\hline Employed & 146 & 97.3 \\
\hline Unemployed & 4 & 2.6 \\
\hline \multicolumn{3}{|l|}{ Socio economic status } \\
\hline Upper Class & 37 & 24.7 \\
\hline Upper Middle & 107 & 71.3 \\
\hline Lower Middle & 6 & 4.0 \\
\hline Upper Lower & 0 & 0 \\
\hline Lower & 0 & 0 \\
\hline \multicolumn{3}{|l|}{ Type of family } \\
\hline Joint & 53 & 35.3 \\
\hline Nuclear & 97 & 64.7 \\
\hline \multicolumn{3}{|l|}{ Type of school } \\
\hline Government & 50 & 33.3 \\
\hline Private & 100 & 66.7 \\
\hline
\end{tabular}




\begin{tabular}{|l|c|c|c|}
\hline $\begin{array}{l}\text { TABLE } 2 \text { SUBSCALES SCORES OF SDQ IN SCHOOL GOING ADOLESCENTS (N-150) } \\
\text { Behavioural Subset for Mental Health }\end{array}$ & Normal $n(\%)$ & Borderline $n(\%)$ & Abnormal $n(\%)$ \\
\hline Emotional Problems & $133(88.7)$ & $7(4.7)$ & $10(6.7)$ \\
\hline Conduct Problems & $118(72.7)$ & $27(21.3)$ & $5(6.0)$ \\
\hline Hyperactivity & $121(80.7)$ & $16(10.7)$ & $13(8.7)$ \\
\hline Peer Problems & $116(70.7)$ & $27(22.0)$ & $7(7.3)$ \\
\hline Pro Social Behaviour & $136(81.3)$ & $9(12.0)$ & $5(6.7)$ \\
\hline () Parentheses show row percentages & & & \\
\hline
\end{tabular}

\section{TABLE 3 CATEGORIZATION OF STUDY PARTICIPANTS BASED ON THEIR LEVELS OF TOTAL STRENGTH AND DIFFICULTY SCORE FOR INDIVIDUAL BEHAVIOURAL SUBSETS AND COMPARISON ACCORDING TO GENDER}

\begin{tabular}{|c|c|c|c|}
\hline \multirow{2}{*}{$\begin{array}{c}\text { Behavioural Subset for Mental Health } \\
\text { with Levels of Total Strength and } \\
\text { Difficulty Score }\end{array}$} & \multicolumn{2}{|c|}{ Gender } & \multirow{2}{*}{$p$ value } \\
\hline & $\begin{array}{c}\text { Boys }(n=76) \\
n(\%)\end{array}$ & $\begin{array}{c}\text { Girls }(n=74) \\
n(\%)\end{array}$ & \\
\hline \multicolumn{4}{|l|}{ Emotional Problems } \\
\hline Normal & $\begin{array}{l}73(96.1) \\
\{54.9\}\end{array}$ & $\begin{array}{l}60(81.1) \\
\{45.1\}\end{array}$ & \multirow[t]{3}{*}{0.01} \\
\hline Borderline & $\begin{array}{l}1(1.3) \\
\{14.3\}\end{array}$ & $\begin{array}{l}6(8.1) \\
\{85.7\}\end{array}$ & \\
\hline Abnormal & $\begin{array}{l}2(2.6) \\
\{20.0\}\end{array}$ & $\begin{array}{l}8(10.8) \\
\{80.0\}\end{array}$ & \\
\hline \multicolumn{4}{|l|}{ Conduct Problems } \\
\hline Normal & $\begin{array}{l}65(85.5) \\
\{55.1\}\end{array}$ & $\begin{array}{l}53(71.6) \\
\{44.9\}\end{array}$ & \multirow[t]{3}{*}{0.028} \\
\hline Borderline & $\begin{array}{l}11(14.5) \\
\{40.7\}\end{array}$ & $\begin{array}{l}16(21.6) \\
\{59.3\}\end{array}$ & \\
\hline Abnormal & $\begin{array}{l}0(0.0) \\
\{0.0\}\end{array}$ & $\begin{array}{l}5(6.8) \\
\{100.0\}\end{array}$ & \\
\hline \multicolumn{4}{|l|}{ Hyperactivity } \\
\hline Normal & $\begin{array}{l}71(93.4) \\
\{58.7\}\end{array}$ & $\begin{array}{l}50(67.6) \\
\{41.3\}\end{array}$ & \multirow[t]{3}{*}{0.000} \\
\hline Borderline & $\begin{array}{l}4(5.3) \\
\{25.0\}\end{array}$ & $\begin{array}{l}12(16.2) \\
\{75.0\}\end{array}$ & \\
\hline Abnormal & $\begin{array}{l}1(1.3) \\
\{7.7\}\end{array}$ & $\begin{array}{l}12(16.2) \\
\{92.3\}\end{array}$ & \\
\hline \multicolumn{4}{|l|}{ Peer Problems } \\
\hline Normal & $\begin{array}{l}68(89.5) \\
\{58.6\}\end{array}$ & $\begin{array}{l}48(64.9) \\
\{41.4\}\end{array}$ & \multirow[t]{3}{*}{0.001} \\
\hline Borderline & $\begin{array}{l}7(9.2) \\
\{25.9\}\end{array}$ & $\begin{array}{l}20(27.0) \\
\{74.1\}\end{array}$ & \\
\hline Abnormal & $\begin{array}{l}1(1.3) \\
\{14.3\}\end{array}$ & $\begin{array}{l}6(8.1) \\
\{85.7\}\end{array}$ & \\
\hline \multicolumn{4}{|l|}{ Pro-social Behaviour } \\
\hline Normal & $\begin{array}{l}72(94.7) \\
\{52.9\}\end{array}$ & $\begin{array}{l}64(86.5) \\
\{47.1\}\end{array}$ & \multirow[t]{3}{*}{0.18} \\
\hline Borderline & $\begin{array}{l}2(2.6) \\
\{22.2\}\end{array}$ & $\begin{array}{l}7(9.5) \\
\{77.8\}\end{array}$ & \\
\hline Abnormal & $\begin{array}{l}2(2.6) \\
\{40.0\}\end{array}$ & $\begin{array}{l}3(4.1) \\
\{60.0\}\end{array}$ & \\
\hline
\end{tabular}


TABLE 4 ASSOCIATION BETWEEN INDIVIDUAL BEHAVIOURAL SUBSETS SCORES WITH THE TYPE OF SCHOOL OF THE STUDY PARTICIPANTS

\begin{tabular}{|c|c|c|c|}
\hline $\begin{array}{l}\text { Behavioural Subset for Mental Health with } \\
\text { Grading }\end{array}$ & $\begin{array}{l}\text { Private }(n=100) \\
n(\%)\end{array}$ & $\begin{array}{l}\text { Government }(n=50) \\
n(\%)\end{array}$ & $p$ value \\
\hline \multicolumn{4}{|l|}{ Emotional Problems } \\
\hline Normal & $\begin{array}{c}85(85.0) \\
\{63.9\}\end{array}$ & $\begin{array}{c}48(96.0) \\
\{36.1\}\end{array}$ & \multirow[t]{3}{*}{0.093} \\
\hline Borderline & $\begin{array}{l}7(7.0) \\
\{100.0\}\end{array}$ & $\begin{array}{c}0(0.0) \\
\{0.0\}\end{array}$ & \\
\hline Abnormal & $\begin{array}{l}8(8.0) \\
\{80.0\}\end{array}$ & $\begin{array}{l}2(4.0) \\
\{20.0\}\end{array}$ & \\
\hline \multicolumn{4}{|l|}{ Conduct Problems } \\
\hline Normal & $\begin{array}{l}71(71.0) \\
\{60.2\}\end{array}$ & $\begin{array}{c}47(94.0) \\
\{39.8\}\end{array}$ & \multirow[t]{3}{*}{0.005} \\
\hline Borderline & $\begin{array}{c}24(24.0) \\
\{88.9\}\end{array}$ & $\begin{array}{l}3(6.0) \\
\{11.1\}\end{array}$ & \\
\hline Abnormal & $\begin{array}{l}5(5.0) \\
\{100.0\}\end{array}$ & $\begin{array}{c}0(0.0) \\
\{0.0\}\end{array}$ & \\
\hline \multicolumn{4}{|l|}{ Hyperactivity } \\
\hline Normal & $\begin{array}{l}75(75.0) \\
\{62.0\}\end{array}$ & $\begin{array}{c}46(92.0) \\
\{38.0\}\end{array}$ & \multirow[t]{3}{*}{0.037} \\
\hline Borderline & $\begin{array}{c}13(13.0) \\
\{81.2\}\end{array}$ & $\begin{array}{l}3(6.0) \\
\{18.8\}\end{array}$ & \\
\hline Abnormal & $\begin{array}{c}12(12.0) \\
\{92.3\}\end{array}$ & $\begin{array}{c}1(2.0) \\
\{7.7\}\end{array}$ & \\
\hline \multicolumn{4}{|l|}{ Peer Problems } \\
\hline Normal & $\begin{array}{c}76(76.0) \\
\{65.5\}\end{array}$ & $\begin{array}{c}40(80.0) \\
\{34.5\}\end{array}$ & \multirow[t]{3}{*}{0.85} \\
\hline Borderline & $\begin{array}{c}19(19.0) \\
\{70.4\}\end{array}$ & $\begin{array}{l}8(16.0) \\
\{29.6\}\end{array}$ & \\
\hline Abnormal & $\begin{array}{l}5(5.0) \\
\{71.4\}\end{array}$ & $\begin{array}{l}2(4.0) \\
\{28.6\}\end{array}$ & \\
\hline \multicolumn{4}{|l|}{ Pro-social Behaviour } \\
\hline Normal & $\begin{array}{c}87(87.0) \\
\{64.0\}\end{array}$ & $\begin{array}{c}49(98.0) \\
\{36.0\}\end{array}$ & \multirow[t]{3}{*}{0.17} \\
\hline Borderline & $\begin{array}{l}9(9.0) \\
\{100.0\}\end{array}$ & $\begin{array}{l}0(0.0) \\
\{0.0\}\end{array}$ & \\
\hline Abnormal & $\begin{array}{l}4(4.0) \\
\{80.0\}\end{array}$ & $\begin{array}{l}1(2.0) \\
\{20.0\}\end{array}$ & \\
\hline
\end{tabular}

\section{Figures}

FIGURE 1 TOTAL DIFFICULTY SCORES IN SCHOOL GOING ADOLESCENTS

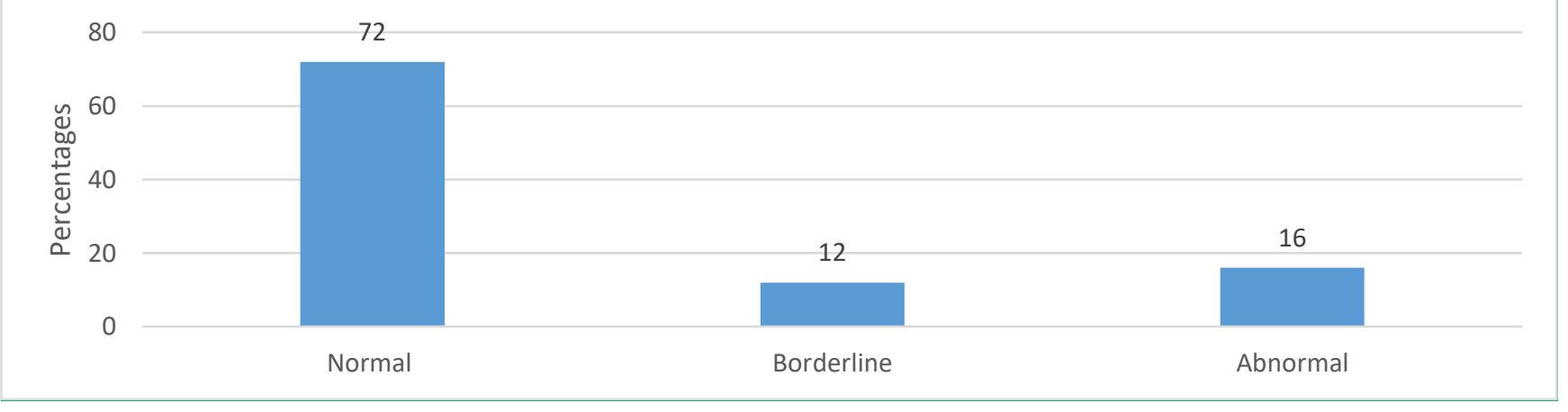

